\title{
The Scientific Basis of Medication Choice in Symptomatic Migraine Treatment*
}

\author{
Peter J. Goadsby
}

\begin{abstract}
With the rapid advances in the treatment of acute attacks of migraine in the last few years and a number of new treatments, has come the practical clinical problem of comparing emerging acute attack therapies alone and with regard to current treatments. Acute migraine therapies can usefully be regarded as non-specific and specific, from the perspective of migraine, since some medicines, such as aspirin or paracetamol, are used to treat pain more broadly. In this review I will compare both non-specific and specific compounds. To some extent the introduction into trial then clinical use of sumatriptan, the first of the $5 \mathrm{HT}_{1 \mathrm{~B} / 1 \mathrm{D}}$ agonists or triptans, brought new standards in both clinical trial design, and execution and clinical outcome. Thus sumatriptan has become the de facto gold standard and will be thus employed here. To be practical the discussion of the new triptans will be limited to those available widely, naratriptan, rizatriptan and zolmitriptan. There are two broad issues when comparing treatments: what end-point should be considered and then, how can different compounds be compared with respect to that end-point. In terms of end-points those used here relate to pain relief because they have been collected robustly in the clinical studies and, fortunately, rapid pain relief is what patients questioned in population-based studies rate highest in an acute attack medicine. Headache pain has been rated on a scale of nil, mild, moderate and severe and success rated as either a response, nil or mild pain, or headache free, nil pain, at two or four hours. The ideal comparison of the triptans would be a randomized controlled clinical trial directly comparing the medicines in each case. Given that these are not available for all the compounds and the well characterised placebo response in acute migraine studies, summary measures have been developed to express the differences between compounds to try and adjust for the varying placebo effect. The two most widely used are the therapeutic gain, response on active medication minus response on placebo, and the number-needed-to-treat (NNT). The NNT is the reciprocal of the therapeutic gain as a proportion. The strengths and weaknesses of this approach will be discussed, including the importance of the calculation of confidence intervals. It can be concluded that our current instruments are rather blunt and patient preference needs much greater study.
\end{abstract}

RÉSUMÉ: Bases scientifiques du choix de la médication dans la migraine symptomatique. Avec les progrès rapides dans le traitement des accès aigus de migraine au cours des dernières années et l'avènement de plusieurs nouveaux médicaments, nous faisons face au problème clinique pratique de l'évaluation de ces nouveaux médicaments par rapport aux médicaments usuels. Les médicaments utilisés pour traiter la crise aiguë de migraine peuvent être divisés à toute fin pratique en médicaments non spécifiques et spécifiques du point de vue de la migraine, certains médicaments tels l'aspirine ou le paracétamol étant utilisés pour traiter la douleur en général. Dans cette revue du sujet, les médicaments non spécifiques et spécifiques seront comparés. Jusqu'à un certain point, les essais cliniques puis l'utilisation courante du sumatriptan, le premier des agonistes du 5HT $1 \mathrm{~B} / 1 \mathrm{D}$ ou triptans, a entraîné l'établissement de nouveaux standards tant dans la conception et l'exécution des essais cliniques que dans les critères d'efficacité clinique. Le sumatriptan est donc devenu de facto l'étalon or et sera ainsi considéré dans cet article. Sur le plan pratique, la discussion des nouveaux triptans sera limitée à ceux qui sont largement disponibles, soit le naratriptan, le rizatriptan et le zolmitriptan, avec quelques références à l'élétriptan qui sera disponible bientôt. Il y a deux grandes questions quand on compare des médicaments: quels critères d'efficacité clinique devraient être utilisés et comment différents produits peuvent être comparés quant à ces critères. Pour ce qui est des critères d'efficacité, ceux qui sont utilisés ici touchent le soulagement de la douleur parce qu'ils ont été recueillis avec robustesse au cours des études cliniques et, fort heureusement, le soulagement de la douleur est ce à quoi les patients interrogés dans les études de population attachent le plus d'importance pour un médicament utilisé dans le traitement d'une crise aiguë. La céphalée a été classifiée sur une échelle allant de nulle, à légère, modérée ou sévère, et le succès a été évalué soit comme une réponse, douleur nulle ou légère, ou sans céphalée, douleur nulle, à 2 ou 4 heures. La comparaison idéale des triptans serait une étude clinique randomisée, contrôlée, comparant directement les médicaments chez chaque patient. Comme ces études ne sont pas disponibles pour toutes les substances et qu'il existe un effet placebo bien caractérisé dans les études sur l'accès aigu de migraine, des mesures sommaires ont été développées pour exprimer les différences entre les substances et pour essayer d'ajuster pour différents effets placebo. Les deux méthodes les plus utilisées sont le gain thérapeutique, la réponse lorsque le patient prend le médicament actif moins la réponse sous placebo, et le nombre de patients devant être traités (NPT). Le NPT est la réciproque du gain thérapeutique exprimé sous forme de proportion. Les forces et les faiblesses de cette approche sont discutées, incluant l'importance du calcul des intervalles de confiance. On peut conclure que les instruments dont nous disposons actuellement sont plutôt frustres et que la préférence des patients doit être étudiée plus à fond.

Can. J. Neurol. Sci. 1999; 26: Suppl. 3-S20-S26

The evaluation of new medicines for headache is an important issue from several perspectives. Although the pharmacoeconomic issues are becoming increasingly important, I will restrict this discussion to differences of a clinical nature. The review is divided into a discussion of endpoint measures, illustrated by both inter-triptan comparisons and comparisons

\author{
*Modified from ${ }^{1}$ \\ From the Institute of Neurology, The National Hospital for Neurology and \\ Neurosurgery, Queen Square, London UK \\ Reprint requests to: Peter J. Goadsby, Institute of Neurology, Queen Square, London \\ WC1N 3BG UK
}


Table 1: Endpoints used in trials of acute migraine treatment

Endpoint

Headache response or relief
Headache free
Time-to-headache relief
Meaningful headache relief
Complete response

Complete response

\begin{abstract}
At treatment*
moderate/severe

moderate/severe

moderate/severe

moderate/severe

moderate/severe
\end{abstract}

Definition

$\begin{array}{ll}\text { outcome* }_{\text {nil/mild }} & \text { time } \\ \text { nil } & 2 \mathrm{hr} \text { or } 4 \mathrm{hr} \\ \text { nil/mild } & 2 \mathrm{hr} \\ \text { patient defined } & 0->2 \mathrm{hr} \\ \text { nil/mild } & 2 \mathrm{hr} \\ + \text { no recurrence } \S & 24 \mathrm{hr} \\ + \text { no rescue medications } \S & \\ \text { patient takes rescue medication } & 24 \mathrm{hr}\end{array}$

*Headache severity after treatment with test substance at a defined time point.

$\S$ Recurrence: headache worsening to any level within $24 \mathrm{hr}$

$\S \S$ Within $24 \mathrm{hr}$

with non-specific treatments. There will then be a consideration of some summary measures, the therapeutic gain and number needed to treat (NNT) which have been used recently to illustrate differences between compounds.

\section{WHICH ENDPOINT TO USE?}

The issue of which endpoints to use is vexed. Some options are listed in Table 1. This is not exhaustive but illustrates the problem. In essence there is a competition between the need for scientific rigour, particularly in establishing efficacy in a new class of medicines, the core problem that faced the sumatriptan development team, and providing clinically useful information, which is a more pressing need as the triptan class is more clearly established. To some extent this conflict remains one of the great challenges for the next millennium.

The International Headache Society Clinical Trials Committee is currently recommending that the primary efficacy outcome should be headache free at two hours (Tfelt-Hansen, personal communication). Although more rigid definitions have been recommended by the Committee for several years, ${ }^{2}$ the most commonly used definition for the primary endpoint has been the headache response or headache relief endpoint in which the patient treats an attack in the study only if they have a moderate or severe headache that is not improving. They are considered a responder if at 2 or 4 hours they have nil or mild headache. The sumatriptan clinical trial programme used this endpoint $^{3}$ and this has driven competitors to use similar outcome measures to compete with the perceived gold standard. Several issues arise, including the appropriate time (1, 2 or 4 hours), the comparative value of the headache free endpoint and the reporting of the outcomes from the trials, including the need for either confidence intervals or the information with which to calculate them. ${ }^{4}$

\section{WHAT FIXED TIME POINTS SHOULD BE REPORTED?}

\section{Single fixed-time endpoints}

An issue independent to some extent from the endpoint used is when to make the measurement. There is an interaction between the need for the convenience and co-operation of subjects in a clinical trial, along with the need to obtain all relevant information. In terms of time one might argue that, all other things being equal, the most useful endpoint is as soon as possible. Studies using stop-watch timing could be used ideally, but there are real issues of patient compliance as greater demands are made on the participants. This author takes the view that for most patients with a moderately severe, and certainly for almost all patients with severe and disabling migraine, that responses after two hours are generally unacceptable in high end therapies. The natural history of a migraine attack is to terminate. Indeed how attacks terminate is one of the most interesting aspects of migraine pathophysiology in terms of understanding how to design better medicines. ${ }^{5} \mathrm{~A}$ recent study in which, by accident, all patients received placebo, illustrates this concept very beautifully (Figure 1). It can be seen

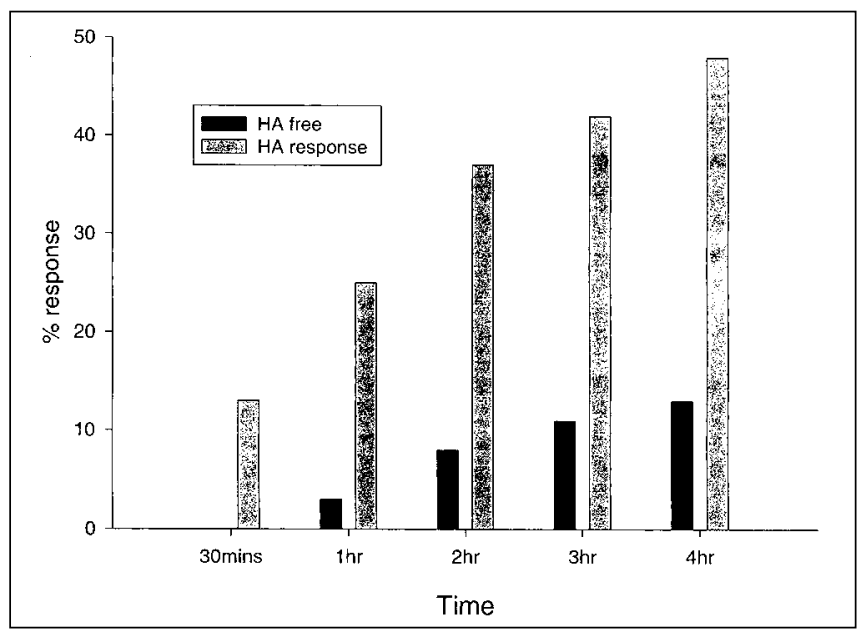

Figure 1: Illustration of the time course of the placebo response in an acute migraine trial. From every time point, 30 minutes onwards, there is a placebo effect seen with the headache relief (moderate/severe pain becomes nil/mild) endpoint. There is a substantial penalty after two hours for collecting noise in the results. This effect is much less prominent when the headache free endpoint is employed but no less valid in proportion for extending studies beyond four hours. 
that treatment with placebo results in a robust headache response of $37 \%$ at two hours rising to $48 \%$ at four hours. ${ }^{6}$ The placebo effect is less of an issue with the headache free endpoint and so the combination of earlier time points using headache free are likely to provide more robust outcomes with smaller numbers of patients. Considering these natural history data along with population-based studies that show patients place high value on rapid resolution of symptoms, ${ }^{7}$ it is very difficult to defend studies with endpoints beyond two hours and hard to understand why they would be reported for triptans.

\section{Survival study methods - time to analysis}

In addition to considering which fixed time point is most appropriate, some recent comparative studies have been analysed using survival methodologies. These methods were used in the sumatriptan $100 \mathrm{mg}$ versus oral Cafergot study ${ }^{8}$ but not again until the rizatriptan development programme. ${ }^{9}$ Literally the analysis looks at how long headache survives from the time of initial treatment. These methods are widely used in other disciplines, such as oncology and multiple sclerosis. ${ }^{10}$ The analysis applied in the rizatriptan studies ${ }^{11}$ is a variation on the Cox Model methodology developed for discrete discontinuous data. ${ }^{12}$ In effect the hazard ratio that is obtained gives the chance that one compound will reach the endpoint in question, here headache relief, sooner than another. The major advantage is that early time points of relief, which are valued highly by patients, are included in the analysis. Fixed time point methods discarding early time points are not clinically sensible, and may blur differences between treatments. The early time points allow a more robust comparison of the population treated, with the potential to detect modest differences. However, the method does not measure rates of response in terms of time so cannot lead to conclusions about speed of onset. This would be best done using stop-watch type studies.

There are also some important assumptions. The first is that when there is a response, there is not worsening during the subsequent measurement period since the patient is counted as a responder and data for worsening would not be included. Secondly, there is the assumption that the hazard ratios at each recorded time-point do not deviate significantly from the overall hazard ratio, proportionality of hazards. A substantial deviation from this assumption reduces the power of the analysis and the assumption should be examined by a time-by-treatment interaction test. Finally, this method assumes that there is a continuous process which allows headache relief to occur at any time in the two hour period after dosing. Methods are described that can deal with discrete time-points so that the patient can record their outcome at specified times.

An example of the time to headache relief analysis would be the comparison between sumatriptan $100 \mathrm{mg}$ and rizatriptan $10 \mathrm{mg} .{ }^{11}$ The outcome was a hazard ratio of 1.21 (95\% CI 1.021.44) demonstrating that over the two hour time period, rizatriptan was more likely to produce headache relief in the next small period than sumatriptan by about $21 \%$.

\section{HEADACHE RESPONSE VERSUS HEADACHE FREE?}

From the first suggestion that the major endpoint for migraine studies should not be complete pain relief there has been controversy. Certainly the International Headache Society
Table 2: An example of endpoint calculations*

\begin{tabular}{lccc}
\hline & \multicolumn{3}{c}{ Response Rate } \\
& calculation & $(\%)$ & $\begin{array}{c}\mathbf{9 5 \%} \text { confidence } \\
\text { interval }\end{array}$ \\
\hline Efficacy & & & \\
placebo & $256 / 1036=$ & 25 & $22-28$ \\
sumatriptan 100mg & $1067 / 1854=$ & 58 & $56-60$ \\
Therapeutic gain & $58-25=$ & 33 & $30-36$ \\
sumatriptan 100mg & $1 / 0.33=$ & 3.0 & $2.8-3.3$ \\
NNT & & & \\
sumatriptan 100mg &
\end{tabular}

*After Tfelt-Hansen ${ }^{4}$; see text for details of calculations.

Clinical Trials Committee incorporated headache free in their initial recommendations, ${ }^{2}$ and recently decided to recommend headache free at two hours as the primary endpoint in clinical trials (Tfelt-Hansen, personal communication). Headache free has a number of advantages, it is unambiguous and therefore does not require explanation, in contrast to headache response or headache relief. Headache free allows treatment of mild headache. In clinical practice patients will not necessarily wish to wait until they have moderate or severe headache to treat. The headache response construct demands this as the trigger to treatment, which is artificial. Moreover, headache free seems more sensitive to difference. As an example the dose-response data for headache free and headache response for the zolmitriptan development programme pick out the dose differences more clearly when the headache free endpoint is employed. ${ }^{13}$

The disadvantages of the headache free endpoint include the view that for patients with slowly settling headache, the transition to no pain is difficult to discern and for some patients the reduction in headache pain to mild is a substantial and very beneficial result. Both observations seem reasonable in some patients. Cynically, it could be said that the headache free endpoint generates smaller percentage responses and this is less attractive to industry in terms of marketing. If headache free can dissect the dose-response relationship, perhaps it would serve earlier phase studies better, and more creative patient-focused endpoints might serve phase III studies better in terms of determining meaningful differences between new and established treatments.

\section{HOW TO REPORT STUDIES?}

In the last decade, the results of most acute studies in migraine have been reported as point estimates, the proportion of patients reaching, for example, the headache response endpoint at two hours. An example of these data might be to report a $58 \%$ response at two hours as the outcome from treatment with sumatriptan $100 \mathrm{mg}$. However, point estimates such as this provide no indication of the accuracy of the outcome. As an example, Tfelt-Hansen ${ }^{4}$ provides a meta-analysis of sumatriptan clinical trials and includes $95 \%$ confidence interval calculations. The relevant calculations are shown in Table 2. It is essential that the results of studies are supplied with confidence intervals or the 
patient numbers with which to calculate them, since estimation of the $95 \%$ confidence interval of a proportion is relatively easy.

\section{Confidence interval of the proportion $p^{14}$}

As an example, a patient takes a medication at time 0 in a double-blind placebo controlled study where they may be randomised to placebo or active treatment arms. Two hours after taking the medication they either have a response or do not. The population probability that they will have a response is $\pi$. In a particular study of $n$ patients, $r$ patients respond and therefore the proportion of responders $p=r / n$.

An approximation to the $95 \%$ confidence interval is:

$$
95 \% \text { CIp }=p \pm 1.96 \sqrt{\frac{p(1-p)}{n}}
$$

This is useful if $\mathrm{n}$ is large and may be used particularly if $n p>10$ and $n(1-p)>10$. The exact limits may be obtained from use of the $\mathrm{F}$ distribution and the link between the $\mathrm{F}$ and binomial distributions. For the interested reader the exact limits are: ${ }^{14}$

$$
\begin{aligned}
& 95 \% \text { Lower }=\frac{r}{r+(n-r+1) F_{0.025,2 n-2 r+2,2 r}} \\
& 95 \% \text { Upper }=\frac{r+1}{r+1+(n-r) F_{0.025,2 r+2,2 n-2 r}^{-1}}
\end{aligned}
$$

\section{Particular endpoints of CliniCal interest?}

Prescribers, payers and patients alike may have other endpoints that are of interest in a clinical trial. Most studies in acute migraine record information on the associated symptoms, such as nausea, photophobia and phonophobia and give an indication of return to normal function (Table 3). Associated symptoms almost without variation track the pain outcome and

\begin{tabular}{|c|c|}
\hline Table 3: Clinical parameters usec & $\mathrm{d}$ as endpoints \\
\hline Endpoint & Comment \\
\hline Relief of pain & Partial (nil or mild pain) \\
\hline & Compete (nil pain) \\
\hline Relief of migraine-related symptoms & - Nausea \\
\hline & - Photophobia \\
\hline & - Phonophobia \\
\hline Relief of functional impairment & May be partial or complete \\
\hline Time-to analysis & Survival curve methods \\
\hline Consistency analysis & - Placebo controlled \\
\hline & - Open label \\
\hline Tolerability & Non-serious adverse events \\
\hline Absolute safety & - Biochemical/haematological tests \\
\hline & - Electrocardiography \\
\hline & - Serious adverse event tracking \\
\hline
\end{tabular}
seldom add much to the pain analysis in terms of separating compounds. A possible exception are the data for early relief of nausea with rizatriptan ${ }^{11}$ which may be related to its relatively poor activity at the $5 \mathrm{HT}_{1 \mathrm{~A}}$ receptor ${ }^{15}$ which in turn has some role in nausea generation. ${ }^{16,17}$ Two issues arguably of some importance are consistency of response and side effect potential. Other issues which could be considered are the concept of meaningful relief ${ }^{18}$ and the use of individual patient preference studies to compare triptans.

\section{Consistency studies}

Consistency in acute migraine studies may be derived from two sources, placebo-controlled blinded studies or open label use. While open label use mimics clinical practice and it is reassuring to know that a medicine that works will continue to work, ${ }^{19-21}$ this is somewhat self-fulfilling in these studies. Patients in these studies have had success in controlled studies and then keep taking medication for 6-12 months. Logically most patients who stay in open label studies will have good responses or they would drop out. It would be of interest to see more reporting of drop-out rates in these studies. To be able to compare consistency, either head-to-head comparisons or relative comparisons from placebo-controlled trials are needed. There have been two well controlled consistency studies published. The first for sumatriptan $25 \mathrm{mg}, 50 \mathrm{mg}$ and $100 \mathrm{mg}$ against placebo, showing that $61 \%$ of patients responded in $2 / 3$ attacks for sumatriptan 50mg. ${ }^{22}$ Another was completed in the rizatriptan development programme, done as a three-way placebo controlled cross-over study and demonstrating that $86 \%$ of patients responded in $2 / 3$ attacks. ${ }^{23}$ Consistency is important to patients ${ }^{7}$ and should form part of the overall assessment of any new compound.

\section{Adverse event reporting}

For some patients pain control comes at a considerable price in terms of side effects, and such patients place a great premium on a well tolerated medication. Unfortunately adverse event rates from one study to another are not always comparable given that different developers have used variations in the manner of collection and coding of adverse events. One can use all causality adverse event reporting as a crude measure of tolerability bearing this caveat in mind, but not as a measure of safety. By using them in this way the relative aggravation of any adverse event is not measured, but this is offset somewhat by the large sample sizes running into thousands of patients for each of the triptan development programmes. It is a useful first approximation which does not seek to minimise side effect variability or clinical significance. Adverse event rates can be used to perform dose selection, trying to optimise efficacy against the side effect price, although again it is important to have some indication of adverse event severity to make sensible decisions.

As an example, the selection of the $2.5 \mathrm{mg}$ dose $\mathrm{e}^{24,25}$ of zolmitriptan after initial strong development of the $5 \mathrm{mg}$ dose $\mathrm{e}^{26}$ is a case in point. The data demonstrate that the $2.5 \mathrm{mg}$ dose, while on the shoulder of the efficacy-response relationship, lags behind the $5 \mathrm{mg}$ dose in terms of adverse events and thus represents a good balance for many patients. The naratriptan development programme developed this concept further by weighting dose selection for tolerability more strongly than for efficacy. ${ }^{27}$ The outcome is, in general terms, the best tolerated of the currently available triptans. 

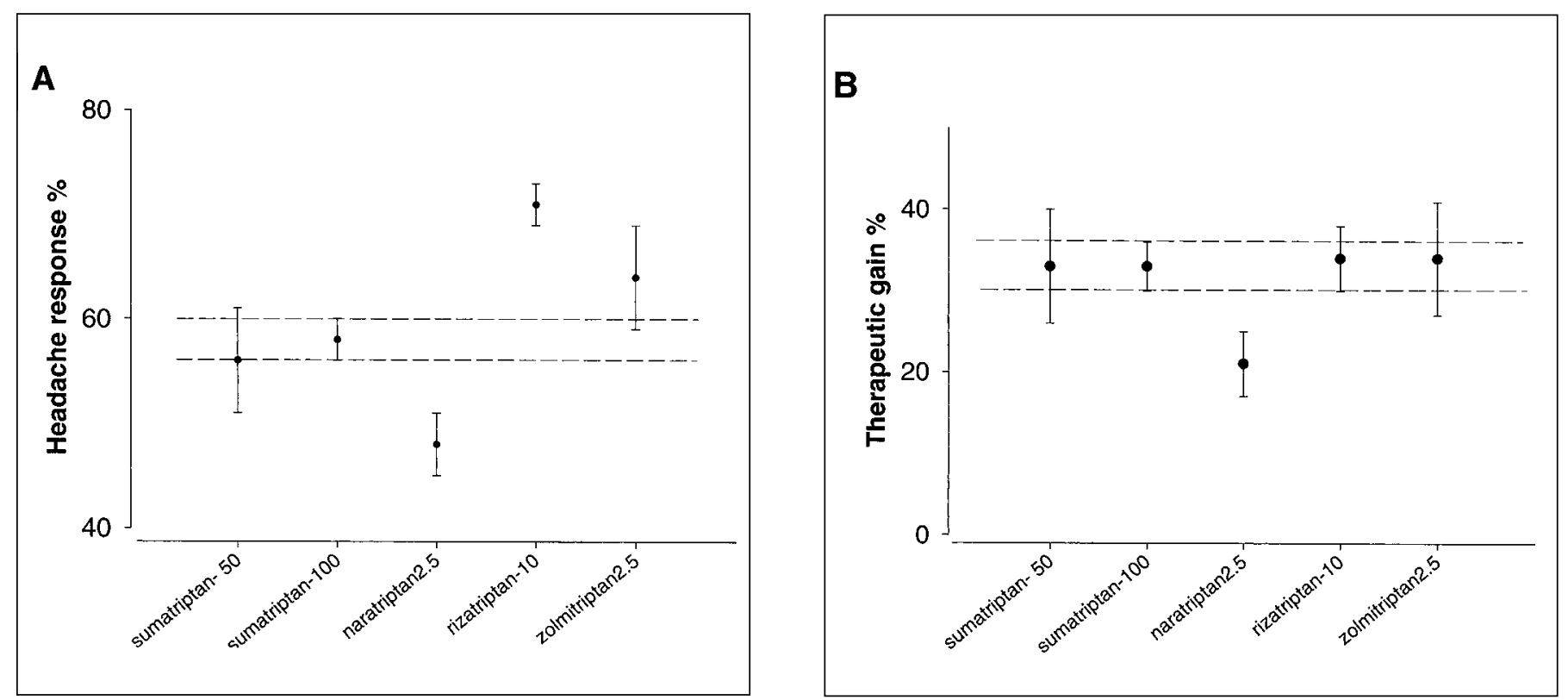

Figure 2: Comparison of headache response rates for doses of triptans currently used in clinical practice. In Panel A the uncorrected headache response is shown and in Panel B the therapeutic gains. It is clear from the perspective of therapeutic gain calculations that sumatriptan, rizatriptan and zolmitriptan are very similar at two hours, with only naratriptan performing consistently less well. The latter outcome is in line with direct comparator studies. ${ }^{29}$ Each data point is presented with the $95 \%$ confidence interval and the dashed line is for reference to sumatriptan 100mg.

\section{Safety}

All the triptans currently used, sumatriptan, naratriptan, rizatriptan and zolmitriptan, and those in late development, eletriptan, almotriptan and frovatriptan, are $5 \mathrm{HT}_{1 \mathrm{~B}}$ agonists ${ }^{15}$ and thus constrict human coronary vessels to some degree. ${ }^{28}$ All seem relatively safe but none are safer than each other. Some are better tolerated, and this applies most clearly to naratriptan, but this must not be confused with cardiovascular safety which is identical across the class.

\section{THERAPEUTIC GAIN AND NUMBER NEEDED TO TREAT (NNT)}

There has been some interest in recent times in summary measures that try to express the overall utility of a medication and perhaps more so for new medications where cost-benefit considerations are becoming more important. In terms of comparing new medicines a randomized controlled clinical trial remains the gold standard for comparing drugs. However, these do not exist for all the currently used acute migraine treatments and so some summary measures provide first approximations of the general response of a compound. ${ }^{13}$ Approximations generally need to be used with caution and these measures are certainly covered by that warning.

\section{Therapeutic gain}

This is the simple calculation of subtracting the placebo response from a randomized trial away from the active response to try to estimate how much of the effect seen is due to the compound. For any comparison of therapeutic gains there is an assumption that the effects of placebo are additive, and this is not at all clear. There is a also a ceiling effect that works against the calculation to minimize differences in that one almost never sees a 100\% headache response rate and indeed not much more than
$80 \%$ for oral triptan studies, but the placebo responses vary between $15 \%$ and $45 \%$, thus telescoping to some extent the outcome of therapeutic gain calculations. This is less of an issue if one does a meta-analysis across large numbers of patients since the placebo responses are reasonably consistent.

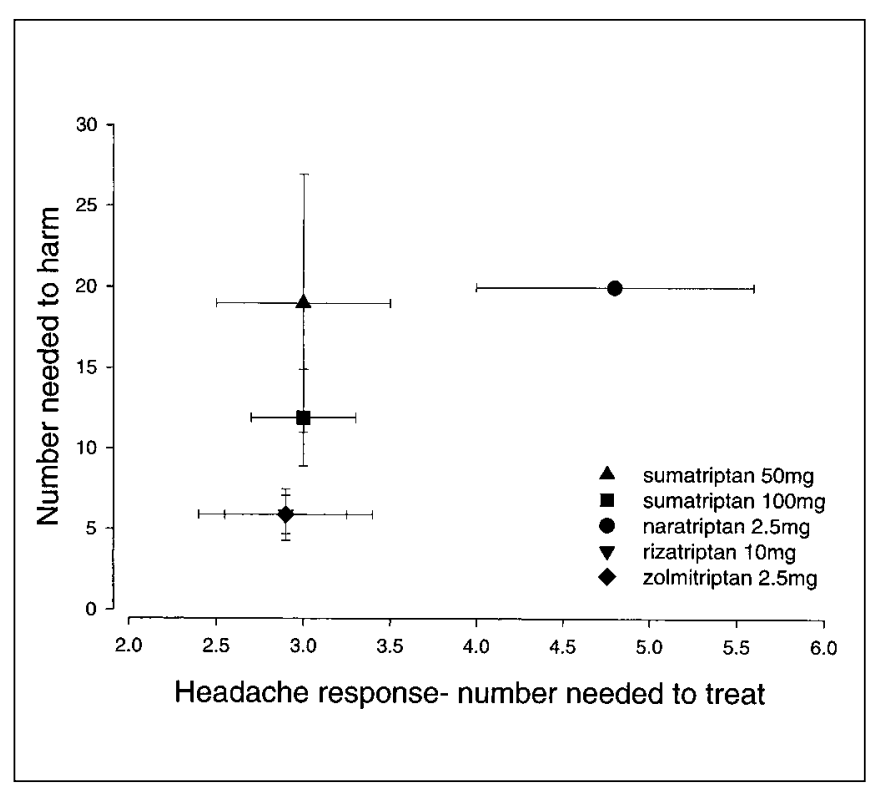

Figure 3: Comparison of number needed to treat (NNT) and number needed to harm (NNH) for the triptans. This analysis suggests they are very similar in both dimensions with only naratriptan being demonstrably different. There is no confidence interval for naratriptan adverse events (NNH) because the difference is so small from placebo rendering the calculations unhelpful. Note that the symbols for zolmitriptan and rizatriptan are superimposed. 
Across the naratriptan, rizatriptan and zolmitriptan development programmes for the headache response endpoint at two hours, for which there is the most data, the therapeutic gain outcomes were $21 \%(17-25 \%), 34 \%(30-38 \%)$ and $34 \%(27-$ $41 \%$ ), respectively. This compares with 33\% (30-36\%) for the published meta-analysis of the sumatriptan studies. ${ }^{4}$ It should be remarked that confidence intervals for the differences between a proportion can be calculated and a typical calculation is listed in Table 3. Given a response to placebo (p) and active treatment (a), the therapeutic gain is $p$ - $a$, and the confidence interval for that difference would be: ${ }^{14}$

$$
95 \% \text { Confidence }(p-a)=(p-a) \pm 1.96 \sqrt{\frac{p(1-p)}{n}+\frac{a(1-a)}{m}}
$$

A comparison of the two hour headache response rates for sumatriptan, naratriptan $2.5 \mathrm{mg}$, rizatriptan $10 \mathrm{mg}$ and zolmitriptan $2.5 \mathrm{mg}$ is shown in Figure 2 and illustrates the potential benefit of the therapeutic gain calculation in terms of correcting for placebo effects. It remains true in clinical practice that the triptans are different and thus Figure 2 illustrates the crude nature of these types of comparisons which fail to reveal differences that will be reported in clinic.

\section{Number needed to treat (NNT)}

The NNT is the reciprocal of the difference between the response on active medication and that on placebo taken as a proportion. It is no more than the inverse of the therapeutic gain when expressed as a proportion. The calculation for sumatriptan is illustrated in Table 2. Similarly, adverse event rates can be summarized by subtracting the placebo to derive a number needed to harm (NNH). This is an unfortunate term since most adverse events in acute migraine trials are mild and transient, and certainly do no harm. However, this is the use of the term and is not a big issue if it is adequately explained. All the problems that were outlined above apply to NNT calculations, especially the limitations. A particular danger with NNT calculations is to see them expressed without confidence intervals as though the one number summarized what is known about the compound. The folly of this is illustrated in Figure 3. NNTs are point estimates and as such they have error. Moreover, the error can be large and important when it overlaps for two compounds and suggests there may actually be no difference between them. NNT calculations have been used as crude measures of cost per effective treatment by multiplying by the dose cost, but again without confidence intervals this calculation is almost completely meaningless and indeed may be deceptive.

\section{CONCLUSIONS}

The study of migraine in clinical trials has come a long way in the last decade with the standardization of patient groups and some very considerable similarities in entry and endpoint measurements across development programmes for new medicines. Unfortunately, the endpoints we use are somewhat crude. Migraine is much more than headache so that by measuring headache relief as an endpoint there is much about the new treatments that is not captured. The challenge for the next millennium is to understand the benefits, and disadvantages, of the current treatments from the patients' perspective so that we can tease out important differences between these compounds, design better studies and ultimately make evidence-based decisions when selecting treatments for acute migraine.

\section{ACKNOWLEDGMENTS}

The work of the authors reviewed herein has been supported by the Wellcome Trust and the Migraine Trust. PJG is a Wellcome Senior Research Fellow.

\section{REFERENCES}

1. Goadsby PJ. Clinical effectiveness of migraine therapy: the NNT and therapeutic gain methods. In: Goadsby PJ, Dowson AJ, Miles A, eds. Key Advances in Effective Migraine Management. Oxford: Radcliffe Medical Press, 1999:in press.

2. The International Headache Society Committee on Clinical Trials in Migraine. Guidelines for controlled trials of drugs in migraine. Cephalalgia 1991;11:1-12.

3. Pilgrim AJ. Methodology of clinical-trials of sumatriptan in migraine and cluster headache. Eur Neurol 1991;31:295-299.

4. Tfelt-Hansen P. Efficacy and adverse events of subcutaneous, oral, and intranasal sumatriptan used for migraine treatment: a systematic review based on number needed to treat. Cephalalgia 1998; $18: 538$.

5. Goadsby PJ. Current concepts of the pathophysiology of migraine. In: Mathew NT, ed. Neurologic Clinics of North America. Philadelphia: W.B. Saunders, 1997;15:27-41.

6. Jhee SS, Salazar DE, Ford NF, et al. Monitoring of acute migraine attacks: placebo response and safety data. Headache 1998;38:3538.

7. Davies GM, Santanello NC, Kramer M, Matzura-Wolfe D, Lipton RB. Determinants of patient satisfaction with migraine treatment. Headache 1998;38:380.

8. The Multinational Oral Sumatriptan and Cafergot Study Group. A randomized, double-blind comparison of sumatriptan and cafergot in the acute treatment of migraine. Eur Neurol 1991;31:314-322.

9. Goadsby PJ. Rizatriptan in the treatment of acute migraine attacks. Prescriber 1999;10:97-109.

10. Prevention of Relapses and Disability by Interferon $\beta-1 \mathrm{a}$ Subcutaneously in Multiple Sclerosis Study Group. Randomized double-blind placebo-controlled study of interferon b-1a in relapsing/remitting multiple sclerosis. Lancet 1998;352:14981504.

11. Tfelt-Hansen P, Teall J, Rodriguez F, et al. Oral rizatriptan versus oral sumatriptan: a direct comparative study in the acute treatment of migraine. Headache 1998;38:748-755.

12. Kalbfleisch JD, Prentice RL. Marginal likelihoods based on Cox's regression and life model. Biometrika 1973;60:267-278.

13. Goadsby PJ. A Triptan too far. J Neurol Neurosurg Psychiatry 1998;64:143-147.

14. Armitage P, Berry G. Statistical Methods in Medical Research. (Third ed.) Oxford: Blackwell Science, 1994.

15. Goadsby PJ. 5-HT ${ }_{1 \mathrm{~B} / 1 \mathrm{D}}$ agonists in migraine: comparative pharmacology and its therapeutic implications. CNS Drugs 1998; 10:271-286.

16. Grof P, Joffe R, Kennedy S, et al. An open study of oral flesinoxan, a 5-HT(1a) receptor agonist, in treatment-resistant depression. Internat Clin Psychopharmacol 1993;8(3):167-172.

17. NewmanTancredi A, Gavaudan S, Conte C, et al. Agonist and antagonist actions of antipsychotic agents at 5- $\mathrm{HT}_{1 \mathrm{~A}}$ receptors: a [S-35]GTP gamma S binding study. Eur J Pharmacol 1998;355(2-3):245-256.

18. Palmer KJ, Spencer CM. Zolmitriptan. CNS Drugs 1997;7:468478.

19. The International $311 \mathrm{C} 90$ Long-term Study Group. The long-term tolerability and efficacy of oral zolmitriptan (Zomig, 311C90) in 
the acute treatment of migraine. An international study. Headache 1998;38:

20. Block GA, Goldstein J, Polis A, Reines SA, Smith ME, The Rizatriptan Multicenter Study Groups. Efficacy and safety of rizatriptan versus standard care during long-term treatment for migraine. Headache 1998;38:764-771.

21. Bomhof MAM, Heywood J, Pradalier A, et al. Tolerability and efficacy of naratriptan tablets with long term treatment (6 months). Cephalalgia 1998;18:33-37.

22. Pfaffenrath V, Cunin G, Sjonell G, Prendergast S. Efficacy and safety of sumatriptan tablets $(25 \mathrm{mg}, 50 \mathrm{mg}$, and $100 \mathrm{mg})$ in the acute treatment of migraine; defining the optimum doses of oral sumatriptan. Headache 1998;38:184-190.

23. Kramer MS, Matzura-Wolfe D, Polis A, et al. A placebo-controlled crossover study of rizatriptan in the treatment of multiple migraine attacks. Neurology 1998;51:773-781.

24. Solomon GD, Cady RK, Klapper JA, et al. Clinical efficacy and tolerability of $2.5 \mathrm{mg}$ zolmitriptan for the acute treatment of migraine. Neurology 1997;49:1219-1225.

25. Rapoport AM, Ramadan NM, Adelman JU, et al. Optimizing the dose of zolmitriptan (Zomig, 311C90) for the acute treatment of migraine. Neurology 1997;49:1210-1218.

26. Dahlof C, Diener HC, Goadsby PJ, et al. Zolmitriptan, a $5 \mathrm{HT}_{1 \mathrm{~B} / 1 \mathrm{D}}$ receptor agonist for the acute oral treatment of migraine: a multicentre, dose-range finding study. Eur J Neurol 1998;5:535543.

27. Goadsby PJ. Naratriptan in the treatment of acute migraine attacks. Prescriber 1997;8:89-97.

28. MaassenVanDenBrink A, Reekers M, Bax WA, Ferrari MD, Saxena PR. Coronary side-effect potential of current and prospective antimigraine drugs. Circulation 1998;98:25-30.

29. Gobel H, Boswell D, Winter P, Crisp A. A comparison of the efficacy, safety and tolerability of naratriptan and sumatriptan. Cephalalgia 1997;17:426. 